\title{
ESTIMATING THE CHANGE OF VEGETATION COVERAGE OF THE UPSTREAM OF MINJIANG RIVER BY USING REMOTE-SENSING IMAGES
}

\author{
Bing DENG ${ }^{1,2}$, Wu-Nian $\mathrm{YANG}^{2 *}$, Jin $\mathrm{HUANG}^{2}$ and Nan $\mathrm{MU}^{3}$
}

\author{
${ }^{1}$ GuiZhou University of Finance and Economics, Guiyang 550025, China \\ ${ }^{2}$ Key Laboratory of Geoscience Spatial Information Technology, Ministry of Land and Resources of the P.R. \\ China, Cheng-du University of Technology, Chengdu 610059, China \\ ${ }^{3}$ Sichuan Institute of Land Planning and Survey, Chengdu 610045, China \\ *Corresponding author: ywn@cdut.edu.cn
}

(Received May 2018; accepted July 2018)

Key words: vegetation coverage change, vegetation index, dimidiate pixel model, the upstream of Minjiang river, China

\begin{abstract}
The upstream of Minjiang River, which was one of the main water sources for Chengdu Plain and the Yangtze River, was selected as the study area in the paper. With a series of cloud-free Landsat TM/OLI images acquired on June 24, 1994 and June 1, 2014, the vegetation coverage of the study area was calculated based on the vegetation index and dimidiate pixel model. The temporal and spatial changes of vegetation coverage were analyzed with digital elevation model and county area. The average vegetation coverage of the study area was decreased from $68.97 \%$ in 1994 to $60.39 \%$ in 2014 . The analysis results showed that vegetation changes were closely related to topographical characteristics. The proportion of vegetation degradation area increased with the elevation increase and vegetation degradation was the most serious at the elevation range from $3500 \mathrm{~m}$ to $4500 \mathrm{~m}$. The vegetation degeneration was the most obvious in Wenchuan County and Songpan County. Geological hazards caused by the earthquake and human disturbance were the main cause of the vegetation degradation and the aridity trend in the study area was another important factor.
\end{abstract}

Palabras clave: cambio en la cobertura vegetal, índice de vegetación, modelo de pixeles divididos, curso alto del río Minjiang, China

\section{RESUMEN}

El curso alto del río Minjiang, que fue una de las principales fuentes de agua para la planicie de Chengdu y el río Yangtse se seleccionó como área de estudio para este trabajo. A partir de una serie de imágenes Landsat TM/OLI sin nubes se calculó el área de cobertura vegetal con base en el índice de vegetación y en el modelo de pixeles divididos (dimidiate pixel model, en inglés). Los cambios espaciales y temporales de la cobertura vegetal se analizaron con un modelo de elevación digital y el área del condado. El promedio de cobertura vegetal del área de estudio disminuyó de $68.97 \%$ en 1994 a $60.39 \%$ en 2014. El análisis de los resultados mostró que los cambios en la vegetación se relacionaron fuertemente con las características topográficas. La proporción del área vegetal degrada se incrementó con la altitud y fue más importante en el rango de 3500 a $4500 \mathrm{~m}$. La degradación de la vegetación fue más evidente en los 
condados de Wenchuan y Songpan.Los riesgos geológicos causados por temblores de tierra y alteraciones humanas fueron la causa principal de la degradación vegetal y la tendencia a la aridez en el área fue otro factor importante.

\section{INTRODUCTION}

The upstream of Minjiang River located in the transition region from Tibetan Plateau to Chengdu Plain in China is one of the main water sources of Chengdu Plain and the Yangtze River (Ye et al. 2002a, Ye et al. 2002b, Yao et al. 2004, Zaidi et al. 2017). This area is characterized by rich vegetation resources and diverse ecological service functions (Tian et al. 2014). The vertical distributions of vegetation and climate in the area are complicated. Its biodiversity is controlled by vertical differences (Yang et al. 2017, Shen et al. 2017, Razali and Said 2017). Moreover, the ecological balance in this area is fragile. Diverse ecosystems are formed under the complex geographic conditions in typical ecological fragile zones in western China (Grzeczka and Szymak 2016, Rogers et al. 2016, Gao et al. 2017). It is not only an important part of the ecological barrier of the upstream Yangtze River, but also an important ecological barrier and the lifeline of water resources of the Chengdu Plain. The ecological conditions of the study region directly affect the quality and quantity of water resources in the Chengdu Plain, the Minjiang River and even ecological environment and social economic development in the Yangtze River (Zhang et al. 2011, Mi et al. 2016, Emelue and Omongbe 2018, Mohammed 2018).

The vegetation coverage is generally defined as the fraction or percentage of the vertical projection of the crown area of vegetation on the ground surface in the reference area (Ts et al. 1998, Gitelson et al. 2002, Guo et al. 2007, Fu and Liu 2017, Liu et al. 2014, Fang et al. 2017, Khan et al. 2018). However, considering the supplementary requirements of remote sensing techniques, vegetation coverage can be defined as the green vegetation area which can be directly detected by the sensor from any view direction (Singh et al. 2018, Lu et al. 2017). In this study, the above definition of vegetation coverage was adopted. Vegetation coverage is an important index depicting the land surface vegetation and is the basic index of the changes of ecological environment and conditions of land surface vegetation (Qin et al. 2006, Ahmad et al. 2017). Vegetation coverage is the important indicator of the regional ecological system and environment change. The study of vegetation coverage is of great significance to hydrology, ecology, and global change (Zhang 2013, Ali et al. 2017). In various traditional ground survey ways of the vegetation coverage, the simplest way is the ocular estimation method (Li 2003, Khan et al. 2017). Because the ocular estimation method is too subjective, a series of sampling methods, such as the sample method, the belt transect method, and the sample point method, have been developed. In order to obtain more accurate data, some sampling instruments have been developed, such as space quantification meter and mobile light meter. Although these methods have improved the measurement accuracy, the operation is inconvenient in the field. With the development of remote sensing technology, remote sensing data now represent an affordable, cost-effective, and standardized source of environmental information and have been widely applied in ecological surveys (Chen et al. 2013, Aslam et al. 2017). Remote sensing allows the measurement of vegetation coverage for the large area. In the common estimation method of vegetation coverage with remote sensing data, the distribution characteristics of vegetation types in pixels were analyzed to simulate the transformation relationship between vegetation index and vegetation coverage (Jia et al. 2013). In this paper, vegetation coverage of the upstream of Minjiang River was estimated by the vegetation index method and dimidiate pixel model with remote sensing data. Moreover, the vegetation coverage change was analyzed with digital elevation model and meteorological data.

\section{STUDY AREA}

Minjiang River originated from the southern foot of Minshan is a large branch of the Yangtze River. The upstream of Mingjiang River is located in Sichuan Province $\left(102^{\circ} 35^{\prime} 18.026^{\prime \prime} \mathrm{E} \sim 104^{\circ} 15^{\prime} 14.817^{\prime \prime} \mathrm{E}\right.$,

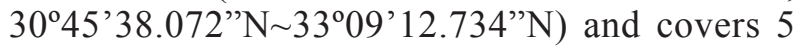
counties (Maoxian, Wenchuan, Lixian, Heishui, and Songpan) with the area of $23037 \mathrm{~km} 2$ (Fig. 1). The upstream of Mingjiang River is $330 \mathrm{~km}$ long. The vertical distribution of the vegetation is complicated in the study area. There are various ecological types, such as boreal forest, arid valley shrubs, subalpine 


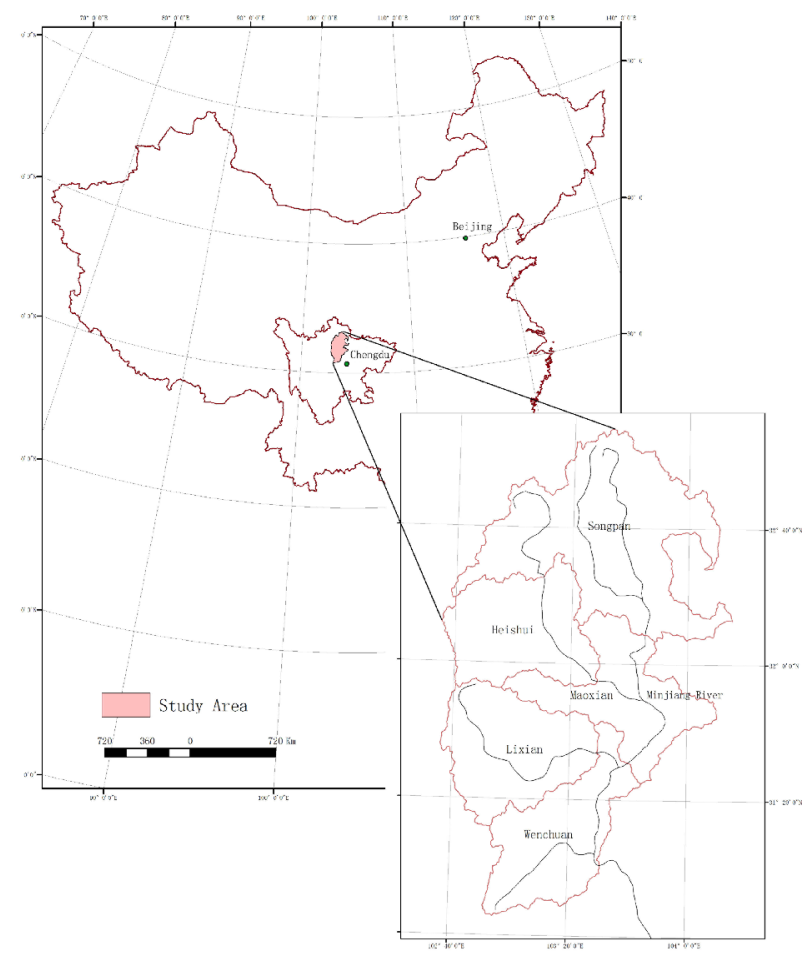

Fig.1. The sketch map of the upstream of Minjiang River, China

forest, subalpine meadow, and subalpine shrub. The study area belongs to the mountain and gorge region in the eastern margin of Tibetan Plateau with various alpine topographies. In the study area, the average annual temperature is $5^{\circ} \mathrm{C} \sim 12^{\circ} \mathrm{C}$; the accumulated temperature is $3143^{\circ} \mathrm{C} \sim 4033^{\circ} \mathrm{C}$ in the southern part and $1148^{\circ} \mathrm{C} \sim 2319^{\circ} \mathrm{C}$ in the northern part; the annual precipitation is $500 \mathrm{~mL} \sim 600 \mathrm{~mL}$; the precipitation is mainly concentrated in the period from May to October.

\section{DATA ACQUISITION}

\section{Image acquisition}

A series of cloud-free Landsat TM/OLI images (WRS path 130 , row 37; path 130, row 38; path 130, row 39) acquired on June 24, 1994 and June 1, 2014 in the upstream of Minjiang River were selected. The spatial resolution of the images is 30 $\mathrm{m}$. Because those images were acquired in the same month (June), the vegetation growth and coverage should be presumably comparable, and these images can avoid the uncertainty in data series resulting from different image acquisition periods (Carlsson et al. 2005). These images can be used to monitor the spatial and temporal changes of vegetation coverage in the upstream of Minjiang River.

\section{DEM data}

The GDEM DEM data with the spatial resolution of $30 \mathrm{~m}$ were downloaded from the website (http:// www.gscloud.cn/). The elevation in the district was calculated based on the DEM data which clearly depicted the topographical characteristics in the study area.

\section{Meteorological data}

According to the phenology of the upstream of Minjiang River, vegetation cover reaches its peak in the period from June to July. However, climate affects the vegetation coverage, especially in dry years. Considering that climate significantly affected vegetation growth, annual precipitation, mean annual temperature, percentage of sunshine, and sunshine duration were selected as the climate indexes. The meteorological data were the mean values obtained from the national meteorological sites in the study area from 1980 to 2012.

\section{METHODS}

\section{Data pre-processing}

Due to the influence of many factors, such as the atmosphere and sensor's pose, remote sensing images recorded by sensors which carried by satellites or planes have measurement errors in geometry and brightness values (Zhang et al. 1990). The images have been processed in the satellite ground station. In order to improve the interpretation accuracy, the remote sensing images were processed ENVI 5.1 software in the paper through several methods, including geometric correction, geometric correction, and projection transformation.

\section{Geometric correction}

In remote sensing imagery technology, the geometric distortion of remote sensing image was caused by the internal or external factors of remote sensing system, including the location of remote sensing platform, the motion of remote sensing platform, terrain fluctuation, the curvature of the Earth's surface, and atmosphere refraction. The positions of targets in remote sensing images are different from the actual positions on the ground. Therefore, the distribution of pixel's rank and size is uneven and the corresponding relationship between the pixel size and the target size on the ground is not precise. Geometric correction 
is to reduce or eliminate the geometric distortion of remote sensing images and to match remote sensing image with the actual geographical space by selecting some ground control points (Coban et al. 2010). Based on the QuickBird image with high spatial resolution, some control points were selected. The precision parameter RMS (Root Mean Square) of control points should be less than 1 . The method of cubic convolution interpolation was adopted in grey value re-sampling of image pixels.

\section{Atmospheric correction}

The purpose of the atmospheric correction is to eliminate the influence of several factors, including atmosphere and light on the clutter reflection, and obtain the real physical model parameters (reflectivity and emissivity of objects, surface temperature, etc.) of the Earth's surface. FLAASH atmospheric correction module and MODTRAN 4+ radiative transfer model in ENVI software was used to perform atmospheric correction. The atmospheric correction of multispectral and hyperspectral data, aerial images, and customized formatting of hyperspectral images may be performed with the atmospheric correction module in FLAASH.

\section{Projection transformation}

TM and OLI remote sensing data in original projection coordinate system (UTM projection, WGS- 84 coordinate system) was transformed into Gauss-Kruger projection with 6 degrees zoning in the $\mathrm{Xi}$ 'an-80 coordinate system.

\section{Vegetation index calculated}

According to the spectral reflection characteristic of the vegetation, vegetation shows strong absorption properties in the visible light red band (RED) and strong reflection features in the near-infrared band (NIR). On the base of different combinations of red bands and near-infrared bands, different vegetation indexes can be obtained to quantitatively reflect the status of the growth of vegetation under certain conditions. As two of the most widely used vegetation indexes, normalized difference vegetation index (NDVI) and enhanced vegetation index (EVI) were calculated by the differences in the values of near-infrared band, red band, and blue band. The two indexes are the optimal indicators of plant growth and spatial distribution density of vegetation. Therefore, NDVI and EVI are commonly used for dynamic monitoring of the growth of vegetation. Terrain shadow and atmospheric disturbance to the image can be largely eliminated with the index of NDVI which is linearly correlated with the vegetation distribution density. The vegetation indexes of NDVI and EVI were selected to calculate the vegetation coverage and then the calculation precisions obtained with the two indexes were compared. The more suitable vegetation index in the study area would be selected to invert the vegetation coverage in this paper.

For TM data of Landsat 5, NDVI and EVI are respectively calculated as follows:

$$
\begin{aligned}
& N D V I_{T M}=\frac{\text { band } 4-\text { band } 3}{\text { band } 4+\text { band } 3} \\
& E V I_{T M}=\frac{2.5(\text { band } 4-\text { band } 3)}{\text { band } 4+6 \text { band } 3-7.5 \text { band } 1+1}
\end{aligned}
$$

For OLI data of Landsat 8, NDVI and EVI are respectively calculated as follows:

$$
\begin{aligned}
& N D V I_{\text {OLI }}=\frac{\text { band } 5-\text { band } 4}{\text { band } 5+\text { band } 4} \\
& E V I_{O L I}=\frac{2.5(\text { band } 5-\text { band } 4)}{\text { band } 5+6 \text { band } 4-7.5 \text { band } 2+1}
\end{aligned}
$$

\section{Construction of dimidiate pixel model}

Dimidiate pixel model is one of the methods to estimate vegetation coverage, and also is one of the simplest linear pixel decomposition model. The dimidiate pixel model is based on the assumption that NDVI/EVI value of a given pixel is a linear combination of NDVI/EVI values of green vegetation and bare soil weighted by their relative proportions (Leprieur et al. 1994). Assuming that a pixel signal consists of the spectrum information from soil and vegetation, spectral dat $(S)$ observed by the sensors is composed of two parts: spectral data of vegetation $\left(S_{\mathrm{v}}\right)$ and spectral data of soil $\left(S_{\mathrm{s}}\right)$. According to Eq. (4), we can get Eq. (5):

$S=S_{v}+S_{s}$

The weight of vegetation coverage is the percentage of vegetation cover surface in pixels and the weight of soil is the percentage of soil area in pixels. For a mixed pixel, the fraction of green vegetation cover in is fc and the fraction of soil cover should be1- fc. The spectral information of a pixel fully covered with the green vegetation is $S_{\text {veg }}$ and the spectral information of a pixel fully covered with bare soil is $\mathrm{S}_{\text {soil }}$. The information contribution by the vegetation composition $\left(\mathrm{S}_{\mathrm{V}}\right)$ in pixels can be represented as:

$S_{v}=S_{v e g} \times f_{c}$ 
The information contribution by the soil composition $\left(S_{\mathrm{s}}\right)$ in pixels can be represented as:

$S_{s}=S_{\text {soil }} \times\left(1-f_{c}\right)$

Therefore, Eq. (5) can be expressed as:

$S=S_{v e g} \times f_{c}+S_{\text {soil }} \times\left(1-f_{c}\right)$

The vegetation coverage can be calculated as:

$f_{c}=\left(S-S_{\text {soil }}\right) /\left(S_{\text {veg }}-S_{\text {soil }}\right)$

According to previous research in vegetation coverage, Eq. (9) is applicable to the remotely sensed data in the reflectance domain and spectral vegetation index domain (Leprieur et al. 1994, Maas 1998). When spectrum information data were expressed with NDVI/EVI, Eq. (9) can be further transformed into:

$f_{c}=\left(N D V I-N D V I_{\text {soil }}\right) /\left(N D V I_{\text {veg }}-N D V I_{\text {soil }}\right)$

$f_{c}=\left(E V I-E V I_{\text {soil }}\right) /\left(E V I_{\text {veg }}-E V I_{\text {soil }}\right)$

Where $N D V I / E V I$ is calculated from remote sensing image; $N D V I_{\text {soi }} / E V I_{\text {soil }}$ is the $N D V I / E V I$ value of bare soil; $N D V I_{\mathrm{veg}} / E V I_{\mathrm{veg}}$ is the $N D V I / E V I$ value of pure vegetation. Then, it is necessary to determine the value of $N D V I_{\text {soil }} / E V I_{\text {soil }}$ and $N D V I_{\text {veg }} / E V I_{\text {veg }}$ to calculate the vegetation coverage $\left(f_{\mathrm{c}}\right)$ in 3 steps. In Step 1, NDVI/EVI data of the image were calculated based on Eqs. (1)-(4) and the histogram of NDVI/EVI data was derived. In Step 2, according to statistics experience, $N D V I / E V I$ value accounting for $5 \%$ pixel of the histogram was set as $N D V I_{\text {soil }} / E V I_{\text {soil }}$, and the $N D V I / E V I$ value accounting for $95 \%$ pixel was set as $N D V I_{\text {veg }} / E V I_{\text {veg }}(\mathrm{Li} 2003)$. In Step 3, the $N D V I_{\text {soil }} /$ $E V I_{\text {soil }}$ and $N D V I_{\text {veg }} / E V I_{\text {veg }}$ values were substituted into Eqs. (10) and (11), to calculate the vegetation coverage. The pixels with negative value were set as 0 and the pixels with the values larger than 1 were set as 1 .

\section{Precision validation}

Although it is difficult to experimentally validate the precision of the calculation results of 1994, the calculation results of 2014 can be verified. The precision validation experiment was carried out from June 25, 2014 and June 28, 2014. The field sampling survey method was usually adopted in precision verification. According to the situation in the study area, the vegetation coverage of each spot was surveyed by visual estimation and typical samples of vegetation coverage were collected for estimation (Zhou et al. 1998, Li et al. 2018). The photos of sample plots were captured in the field and GPS coordinates of the sample plots were recorded. Then the vegetation coverage was estimated by visual observation. According to the coordinate points recorded by GPS, the corresponding sample plots were found and then the average value of 8 adjacent pixels and the sample plot in the image of 2014 was set as the calculated values. Because of the high mountains and precipitous paths, it was difficult to find and investigate the ground plots for this rugged area in the upstream of Minjiang River. Only 31 relatively uniform plots with different land cover types were selected.

Because the number of surveyed plots was not large, in the model, all the data were directly utilized. Fig. 2 shows the statistical scatter plot of the surveyed coverage and remotely sensed coverage. The result indicated that the coverage from dimidiate pixel model was significantly correlated to the values by visual survey $(\mathrm{R} 2=0.809$ and 0.744$)$. The vegetation coverage inverted based on the NDVI showed the higher correlation with the survey data. Therefore, the vegetation index of NDVI was selected in the study.

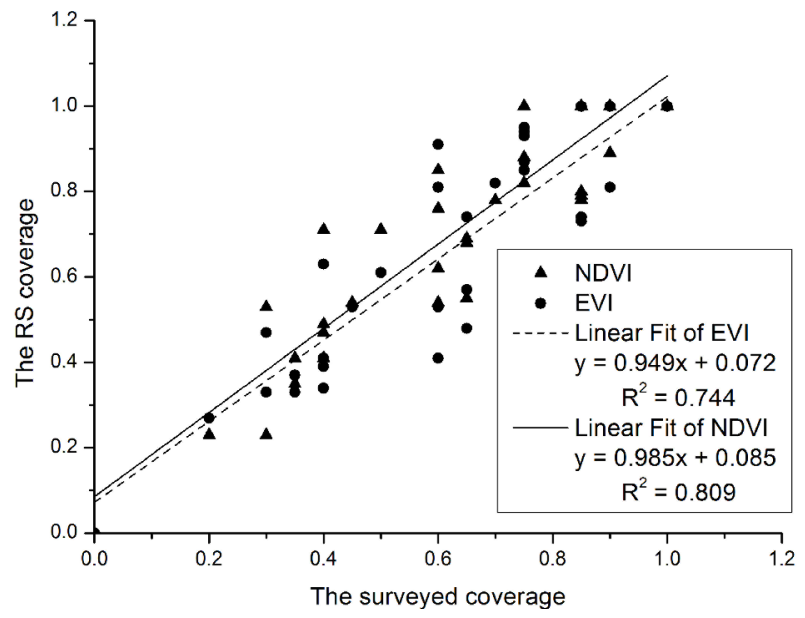

Fig. 2. The relationship between remotely sensed coverage determined by sub-pixel model and the coverage obtained by ground visual estimation

\section{RESULTS}

\section{The change of vegetation coverage}

According to the field investigation in the study area, when $<10 \%$, the study area is covered with bare soil, water, or buildings and there was no vegetation; 


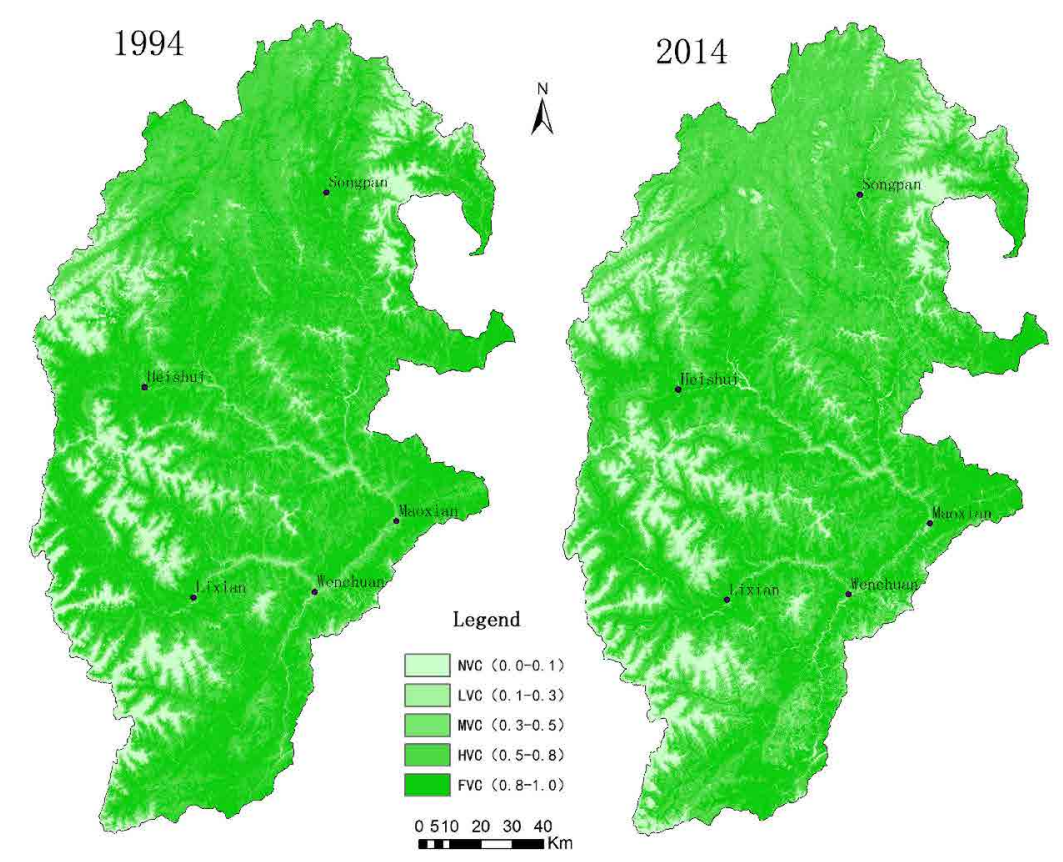

Fig. 3. The vegetation coverage of the study area in 1994 and 2014

when $>80 \%$, the study area is fully covered with vegetation. Classification for vegetation coverage was divided into 5 levels: non-vegetation coverage (NVC) $(<=10 \%)$, low vegetation coverage (LVC) (10\%-30\%), medium vegetation coverage (MVC) (30\%-50\%), high vegetation coverage (HVC) (50\%-
$80 \%)$, and full vegetation coverage (FVC) $(80 \%$ $100 \%$ ) (Peng and Hua 2008, Ding et al. 2009). Fig. 3 shows the vegetation coverage in the above 5 levels.

Table I shows the results of statistical calculations. The average vegetation coverage of the study area was $68.96 \%$ in 1994 and decreased to $60.39 \%$

TABLE I. VEGETATION COVERAGE STATISTICS OF VARIOUS COUNTIES

\begin{tabular}{|c|c|c|c|c|c|c|c|c|c|c|c|}
\hline \multirow[b]{2}{*}{ Counties } & \multirow[b]{2}{*}{ Years } & \multicolumn{2}{|c|}{ NVC } & \multicolumn{2}{|c|}{ LVC } & \multicolumn{2}{|c|}{ MVC } & \multicolumn{2}{|c|}{ HVC } & \multicolumn{2}{|c|}{ FVC } \\
\hline & & $\begin{array}{l}\text { Area } \\
\left(\mathrm{km}^{2}\right)\end{array}$ & $\begin{array}{c}\text { Area } \\
\text { ratio }(\%)\end{array}$ & $\begin{array}{l}\text { Area } \\
\left(\mathrm{km}^{2}\right)\end{array}$ & $\begin{array}{c}\text { Area } \\
\text { ratio }(\%)\end{array}$ & $\begin{array}{l}\text { Area } \\
\left(\mathrm{km}^{2}\right)\end{array}$ & $\begin{array}{c}\text { Area } \\
\text { ratio }(\%)\end{array}$ & $\begin{array}{l}\text { Area } \\
\left(\mathrm{km}^{2}\right)\end{array}$ & $\begin{array}{c}\text { Area } \\
\text { ratio }(\%)\end{array}$ & $\begin{array}{l}\text { Area } \\
\left(\mathrm{km}^{2}\right)\end{array}$ & $\begin{array}{c}\text { Area } \\
\text { ratio }(\%)\end{array}$ \\
\hline \multirow{2}{*}{ Wenchuan } & 1994 & 357.46 & 8.75 & 157.92 & 3.87 & 234.59 & 5.74 & 1249.89 & 30.60 & 2084.14 & 51.03 \\
\hline & 2014 & 418.94 & 10.26 & 271.10 & 6.64 & 428.35 & 10.49 & 1295.78 & 31.73 & 1669.83 & 40.89 \\
\hline \multirow[t]{2}{*}{ Maoxian } & 1994 & 115.41 & 2.96 & 112.94 & 2.89 & 235.25 & 6.03 & 1332.18 & 34.13 & 2107.22 & 53.99 \\
\hline & 2014 & 127.59 & 3.27 & 146.76 & 3.76 & 313.43 & 8.03 & 1286.51 & 32.96 & 2028.71 & 51.98 \\
\hline \multirow[t]{2}{*}{ Lixian } & 1994 & 605.20 & 14.02 & 297.66 & 6.89 & 350.91 & 8.13 & 1245.34 & 28.84 & 1818.89 & 42.12 \\
\hline & 2014 & 615.02 & 14.24 & 372.96 & 8.64 & 464.45 & 10.76 & 1308.34 & 30.30 & 1557.23 & 36.06 \\
\hline \multirow[t]{2}{*}{ Heishui } & 1994 & 317.04 & 7.28 & 243.28 & 5.58 & 320.61 & 7.36 & 1348.00 & 30.95 & 2127.07 & 48.83 \\
\hline & 2014 & 295.44 & 6.78 & 256.46 & 5.89 & 388.22 & 8.91 & 1683.34 & 38.64 & 1732.54 & 39.77 \\
\hline \multirow[t]{2}{*}{ Songpan } & 1994 & 507.93 & 5.99 & 324.20 & 3.82 & 550.54 & 6.49 & 3974.47 & 46.84 & 3128.86 & 36.87 \\
\hline & 2014 & 480.26 & 5.66 & 513.30 & 6.05 & 1265.62 & 14.91 & 4526.05 & 53.34 & 1700.77 & 20.04 \\
\hline \multirow[t]{2}{*}{ Summation } & 1994 & 1903.04 & 7.57 & 1136.00 & 4.52 & 1691.90 & 6.73 & 9149.88 & 36.39 & 11266.18 & 44.80 \\
\hline & 2014 & 1937.25 & 7.70 & 1560.58 & 6.21 & 2860.07 & 11.37 & 10100.02 & 40.16 & 8689.08 & 34.55 \\
\hline
\end{tabular}


in 2014. In 1994, the main vegetation coverage type was FVC and the FVC area was $11266.18 \mathrm{~km}^{2}$ accounting for $44.80 \%$ of the study area. In 2014, the main vegetation type was $\mathrm{HVC}$ and the $\mathrm{HVC}$ area was $10100.02 \mathrm{~km}^{2}$ accounting for $40.16 \%$ of the study area. The degeneration of vegetation coverage was the most obvious in Wenchuan County and Songpan County. From 1994 to 2014, the area of FVC was decreased by $2577.10 \mathrm{~km} 2$, which accounted for $10.23 \%$ of the study area. The areas of NVC, LVC, MVC, and HVC increased more or less and HVC increased the most significantly because the large area of FVC was degraded to HVC.

In order to quantitatively analyze the vegetation degradation in the upstream of Minjiang River, the coverage in the image of 2014 was subtracted by that in the image of 1994 to obtain the degradation image. The vegetation degradation was divided into 7 levels: serious degradation (SD) (the degradation percentage $>30 \%)$, degradation (D) $(15 \% \sim 30 \%)$, light degradation (LD) $(5 \% \sim 15 \%)$, steady coverage (S) $( \pm 5 \%)$, light restoration (LR) $(-15 \% \sim-5 \%)$, restoration (R) $(-30 \% \sim-15 \%)$, and full restoration (FR) $(<-30 \%)$ (Liu et al. 2009). The vegetation coverage transformation image of the upstream of Minjiang River from 1994 to 2014 was illustrated in Fig. 4. The degradation situation of vegetation was serious, and the vegetation degeneration area was $8419.57 \mathrm{~km} 2$, accounted for $33.50 \%$ of the study area. In addition, the vegetation coverage in the majority of the study area was stable and the area of S level was 14722.64 $\mathrm{km} 2$, accounting for $58.55 \%$ of the total area. The restoration area was $2004.79 \mathrm{~km} 2$, accounting for $7.98 \%$ of the study area.

The changes of vegetation coverage are closely related to topographical conditions. Elevation can directly or indirectly reflect the spatial difference among various natural resources, such as the frequency of artificial activities, temperature, light, and rainfall. In this study, the vegetation coverage changes were correlated with the elevation. The elevation in the study area was divided into five levels $(741 \sim 1500 \mathrm{~m}, 1500 \sim 2500 \mathrm{~m}, 2500 \sim 3500 \mathrm{~m}$, $3500 \sim 4500 \mathrm{~m}$, and 4500 7100 m). Table II shows the relationship between the vegetation coverage change and elevation. The results indicated that the area proportion of vegetation degradation increased with the increase in the elevation and the vegetation degradation was the most serious in the elevation range of 3500 4500 $\mathrm{m}$. The vegetation degradation was serious in low the elevation range $(<4500)$ and the probability of the vegetation restoration was also relatively high. The area with the elevation above

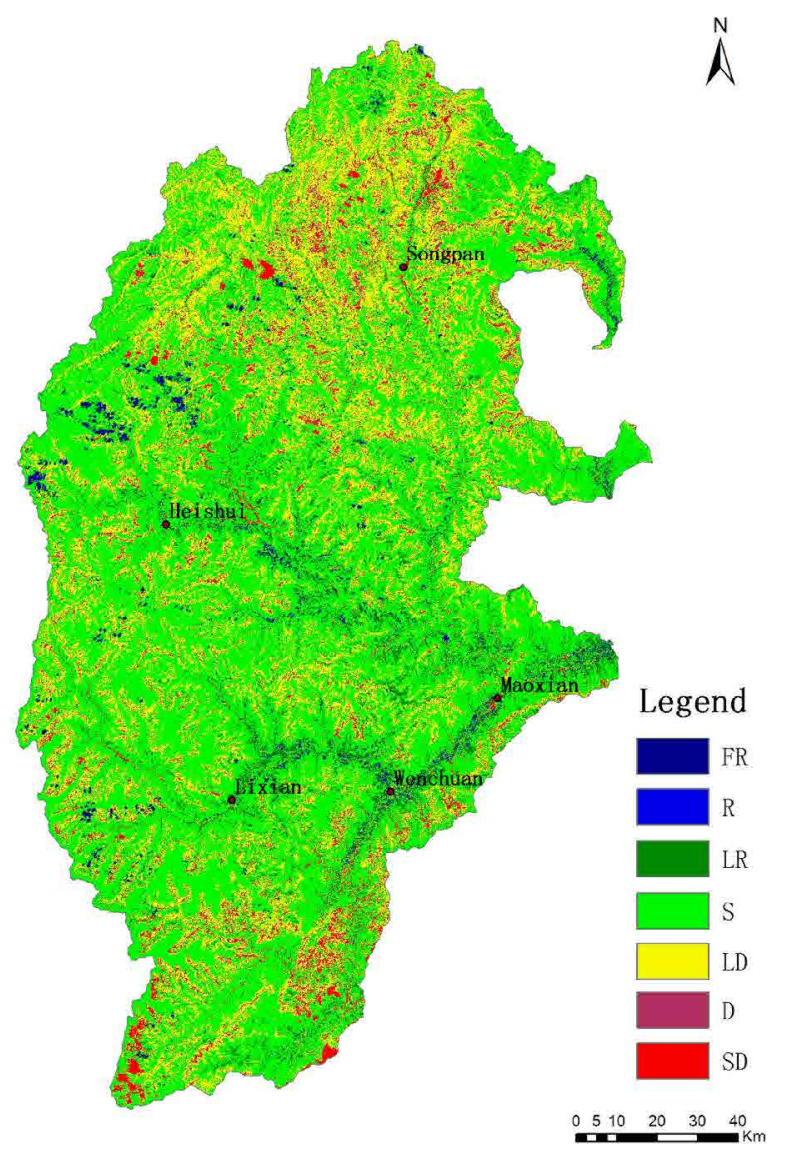

Fig. 4. The vegetation coverage degeneration of the study area from 1994 to 2014

$4500 \mathrm{~m}$ is covered with snow or bare rock and the vegetation coverage is low and also relatively stable. The area with the high elevation $(>4500 \mathrm{~m})$ showed the relative stable vegetation coverage and the area of S level accounted for $95.77 \% \%$ of this area.

\section{Driving forces analysis of vegetation coverage change Influence of earthquake}

The Wenchuan Earthquake on May 21, 2008 caused serious damage to the ecological environment in the study area (Ye et al. 2012, Luo et al. 2013, Xu et al. 2013, Tian et al. 2014, Yang et al. 2014). Landslide, debris flow, and other geological disasters triggered by earthquake caused significant damages to the vegetation in the study region, especially in the valley of Minjiang River. There were a lot of tongue-shaped vegetation degradation areas in Fig. 4 and it was difficult to recover a lot of vegetation degradation areas within a short period. 


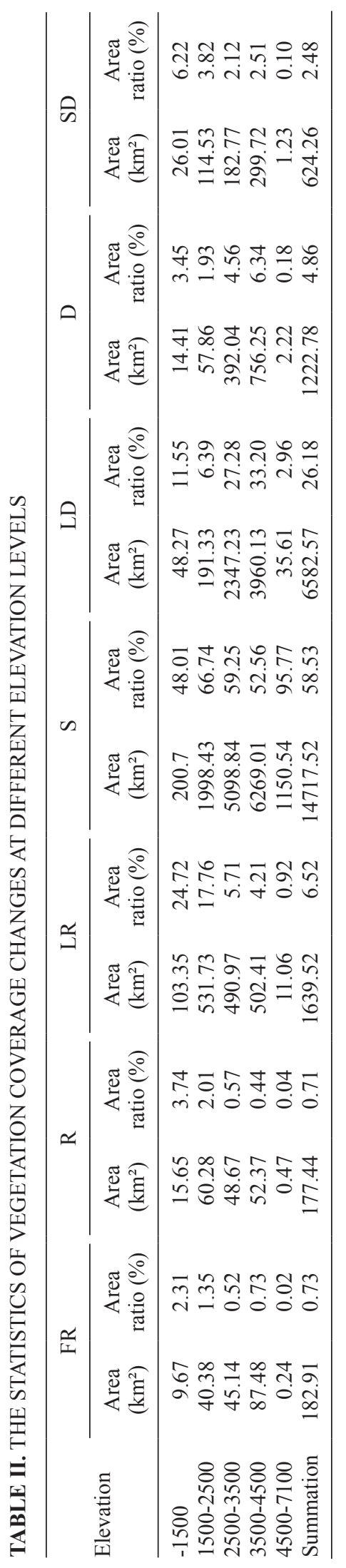

\section{Influence of climate}

Global warming is the most significant feature of climate change over the past more than one hundred years. According to the third assessment report of IPCC (Intergovernmental Panel on Climate Change of the United Nations), the average global temperature rose by $0.4{ }^{\circ} \mathrm{C} \sim 0.8{ }^{\circ} \mathrm{C}$ from 1860 to 2000 (Jiang et al. 2004). Under the background of global warming, China's annual average air temperature rise within the past 50 years was $0.5{ }^{\circ} \mathrm{C} \sim 0.8{ }^{\circ} \mathrm{C}$, which was slightly higher than the global average air temperature rise $\left(0.6 \pm 0.2^{\circ} \mathrm{C}\right)$. The global average temperature rise leads to global precipitation redistribution. The annual average precipitation in China showed the decreasing trend and the regional difference was significant in China. Precipitation reduction in north China was the most significant, followed by the middle and lower reaches of the Yangtze River region and the eastern and southern regions of China (Ding et al. 2005, Ding et al. 2006). The changes in regional climate and vegetation were the consequence of interaction effect of various factors (Zheng et al. 2002a, Zheng et al. 2002b, Li et al. 2011). The vegetation primarily affects the regional climate through transpiration and albedo and the climate change, including the temperature, precipitation, and other factors, can directly affect the vegetation growth. In order to analyze the influence of climate change on vegetation coverage, the data of four meteorological observation sites in the upstream of Minjiang River from 1980 to 2012 were collected. A few climate factors were selected, such as annual precipitation, mean annual temperature, percentage of sunshine, and sunshine duration. The characteristics of climate change in the study area in the past 30 years were illustrated in Fig. 5. The analysis results indicated that both the interannual change and the overall trend of each climate factor were obvious. The aridity trend in the study region was complex. The annual precipitation was in the overall decreasing trend and mean annual temperature was in the rising trend. Besides, the decreases in percentage of sunshine and sunshine duration had negative impacts on vegetation growth. The aridity trend in the study region might be another important factor.

\section{Influences of human activities}

The vegetation coverage under natural conditions might be relatively steady, but frequent human activities might cause the degeneration of vegetation in the study area (Peng et al. 2012). The serious vegetation degradation in the regions with the low altitude $(<1500 \mathrm{~m})$ might be partly caused by human activities, 

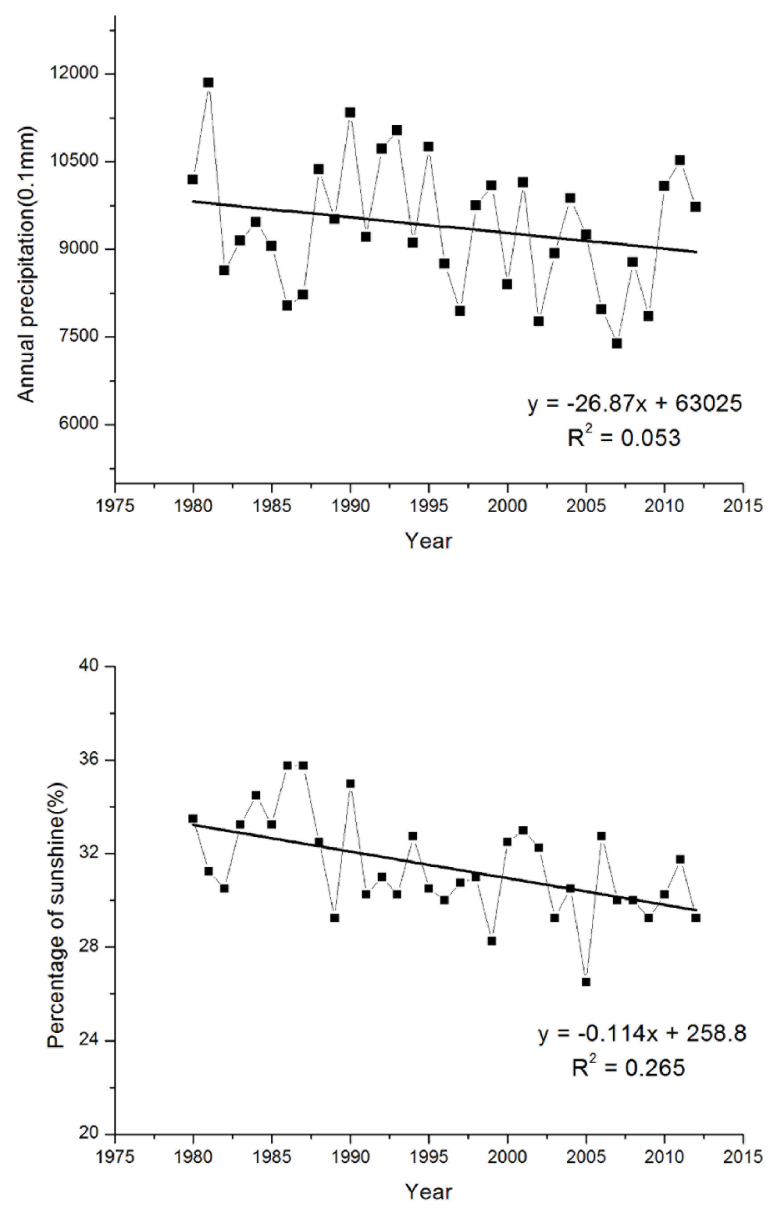

Fig. 5. The trend analysis of climate factors

including the construction of hydropower stations, human deforestation, the construction of roads and railways, and mining activities of ore and sand.

\section{Influences of policy}

After the Wenchuan Earthquake, a series of ecological restoration and reconstruction projects were launched in the earthquake-stricken area. These projects had positive impacts on the recovery of ecological environment.

\section{CONCLUSIONS}

The vegetation coverage of the upstream of Minjiang River was calculated based on vegetation index and dimidiate pixel model with remote sensing images. The result of precision evaluation showed that calculation results were basically consistent with survey results and that the dimidiate pixel model based on vegetation index could be used to extract
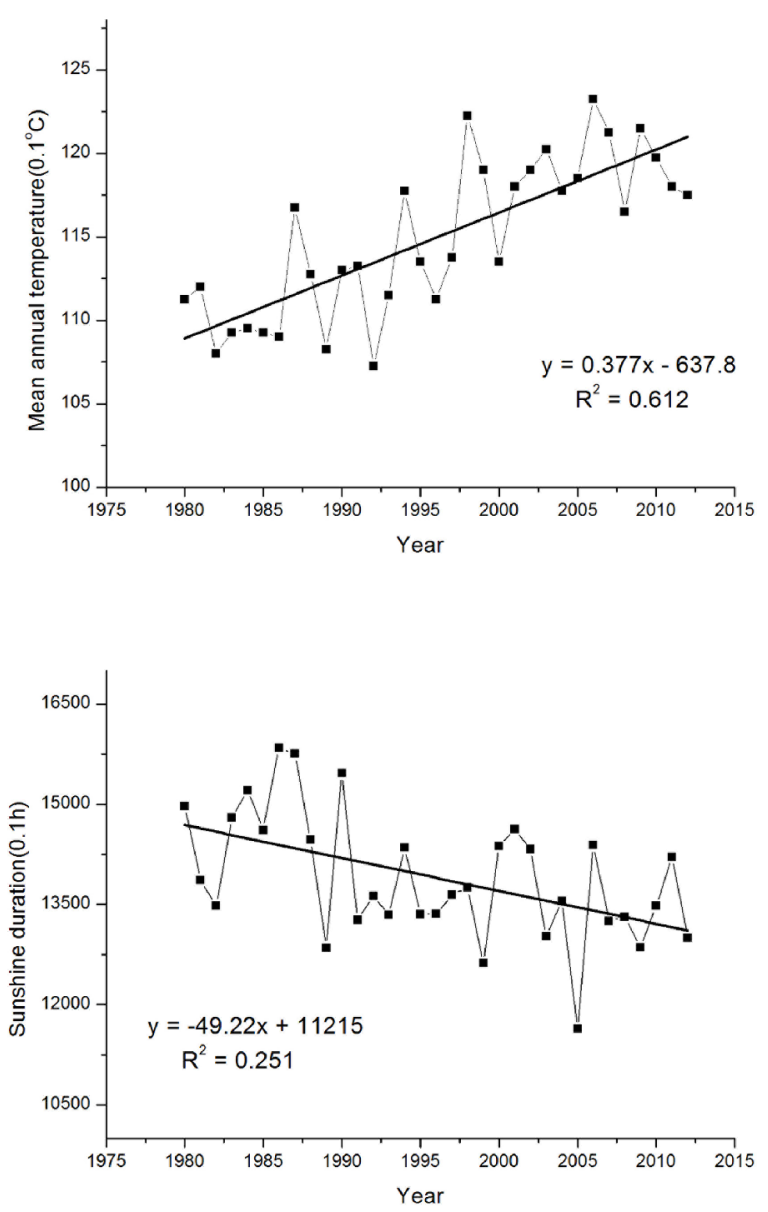

the vegetation coverage in the study area. The vegetation coverage in the study area was decreased from $68.97 \%$ in 1994 to $60.39 \%$ in 2014 . FVC area was reduced most significantly and the degeneration of vegetation coverage was the most obvious in Wenchuan County and Songpan County. The vegetation degradation in the area with the low elevation $(<4500$ $\mathrm{m}$ ) was more serious than that in the area with the high elevation $(>4500 \mathrm{~m}$ ) according to the analysis results of the vegetation coverage change and the DEM. In general, natural environmental changes and human activities are the main driving forces associated with vegetation coverage change. In this study, natural and contrived factors were analyzed. A series of geological hazards caused by the earthquake led to devastating damages to the vegetation in the study area. Obvious aridity trend in the study area was another important factor for vegetation degradation. Furthermore, engineering construction and deforestation significantly affected the vegetation coverage in the study area. 
Under the natural state, vegetation restoration is a long process. In order to accelerate the restoration process of the vegetation damaged in the Wenchuan Earthquake, artificial vegetation regeneration may be adopted to accelerate natural regeneration. In the meanwhile, artificial vegetation destruction activities should be banned. The appropriate climate environment can promote the vegetation growth. In turn, vegetation can adjust local climate, making the climate environment more appropriate.

In this study, the climate change trend was analyzed. The influences of climate change on vegetation coverage change will be studied in the future work.

\section{ACKNOWLEDGMENTS}

The research was supported by Research Fund for the Natural Science Foundation, China (41671432) and the open research funded projects of Key Laboratory of Geoscience Spatial Information Technology, Ministry of Land and Resources of the P.R. China, Chengdu University of Technology(KLGSIT2016-05), The introduction of talent research projects of GuiZhou University of Finance and Economics of the year of 2017.

\section{REFERENCES}

Ahmad N., Hussain T., Awan A.N., Sattar A., Arslan C., Tusief M.Q. and Mariam Z. (2017). Efficient and Eco-friendly Management of biodegradable Municipal Solid Waste (MSW) using naturally aerated Windrow Composting Technique in District Lahore Pakistan. Earth Science Pakistan. 1(1), 01-04.

Ali S.S., Ijaz N., Aman N. and Noor M. (2017). Feasibility Study of Low Density Waste Plastic in Non-Load Bearing Asphalt Pavement in District Faisalabad. Earth Sciences Pakistan. 1(2), 14-15.

Aslam S., Rahman S.U., Sabir Z. and Maqbool B. (2017). Evaluation of Cosmetics for Their Potential Contaminants and Drug Resistant Microorganisms. Acta Scientifica Malaysia. 1(2), 16-19.

Carlsson A.L.M., Bergfur J. and Milberg P. (2005). Comparison of data from two vegetation monitoring methods in semi-natural grasslands. Environmental Monitoring and Assessment. 100 (1-3), 235-248.

Chen W., Sakai T., Moriya K., Koyama L. and Cao C.X. (2013). Estimation of Vegetation Coverage in Semiarid Sandy Land Based on Multivariate Statistical Modeling Using Remote Sensing Data. Environmental Modeling \& Assessment. 18 (5), 547-558.
Coban H.O., Koc A. and Eke M. (2010). Investigation on changes in complex vegetation coverage using multitemporal landsat data of Western Black Sea region--a case study. Journal of Environmental Biology. 31 (1-2), 169-178.

Ding M.Q., Chen S.L. and Guo Y.K. (2009). Assessment on the vegetation coverage after land reclamation based on RS (in Chinese). China land science. 23 (11), 72-75.

Ding Y.H., Li Q.P. and Dong W.J. (2005). A numerical simulation study of the impacts of vegetation changes on regional climate in China (in Chinese). Acta Meteorologica Sinica. 63 (05), 613-621.

Ding Y.H., Ren G.Y., Shi G.Y., Gong P., Zheng X.H., Zhai P.M., Zhang D.E., Zhao Z.C., Wang S.W., Wang H.J., Luo Y., Chen D.L., Gao X.J. and Dai X.S. (2006). National assessment report of climate change(I): Climate change in China and its future trend (in Chinese). Advances in climate change research. 2(01), 3-8.

Emelue G.U. and Omonzogbe E.A. (2018). Growth Performance of African Giant Land Snails (Archachatina Marginata) Fed with Feed Formulated with Different Calcium Sources. Malaysian Journal of Sustainable Agriculture. 2(1), 1-4.

Fang M., Ju W., Zhan W., Cheng T., Qiu F. and Wang J. (2017). A new spectral similarity water index for the estimation of leaf water content from hyperspectral data of leaves. Remote Sensing of Environment. 196, 13-27.

Fu H.L. and Liu X.J. (2017). Research on the Phenomenon of Chinese Residents' Spiritual Contagion for the Reuse of Recycled Water Based on SC-IAT. Water. $9(11), 846$.

Gao W., Kanna M.R.R, Suresh E. and Farahani M.R. (2017). Calculating of degree-based topological indices of nanostructures. Geology, Ecology, and Landscapes. 1(3), 173-183.

Gitelson A.A., Kaufman Y.J., Stark R. and Rundquist D. (2002). Novel algorithms for remote estimation of vegetation fraction. Remote Sensing of Environment. 80(01), 76-87.

Grzeczka G. and Szymak P. (2016). The hardware implementation of demonstrator air independent electric supply system based on pem fuel cell. Polish Maritime Research. 23(4), 84-92.

Guo Z.J., Yan G.J., Feng X., Wang Y.Z. and Zhang X.Y. (2007). Analysis on angular effects of vegetation fraction cover estimation based on remote sensing data (in Chinese). Journal of Beijing Normal University (Natural Science). 43(03), 343-349.

Jia K., Yao Y.J., Wei X.Q., Gao S., Jiang B. and Zhao X. (2013). A review on fractional vegetation cover estimation using remote sensing (in Chinese). Advances in earth science. 28(07), 774-782. 
Jiang D.B., Wang H.J. and Lang X.M. (2004). East asian climate change trend under global warming background (in Chinese). Chinese journal of geophysics. 47(04), 590-596.

Khan F., Khan M.I., Khan S., Zaman M.A.U., Rasheed H. and Khan A.R. (2018). Evaluation of Agronomic Traits for Yield and Yield Components in Wheat Genotypes with Respect To Planting Dates. Malaysian Journal of Sustainable Agriculture. 2(1), 7-11.

Khan I.U., Sajid S., Javed A., Sajid S., Shah S.U., Khan S.N. and Ullah K. (2017). Comparative Diagnosis Of Typhoid Fever By Polymerase Chain Reaction And Widal Test In Southern Districts (Bannu, Lakki Marwat And D.I.Khan) Of Khyber Pakhtunkhwa, Pakistan. Acta Scientifica Malaysia. 1(2), 12-15.

Leprieur C. (1994). Verstraete MM, Pinty B, Evaluation of the performance of various vegetation indices to retrieve vegetation cover from AVHRR data. Remote Sensing Review. 10(4), 265-284.

Li H.X., Liu G.H. and Fu B.J. (2011). Response of vegetation to climate change and human activity based on NDVI in the Three-River Headwaters region (in Chinese). Acta Ecologica Sinica. 31(19), 5495-5504.

Li M.M. 2003. The method of vegetation fraction estimation by remote sensing. Institute of remote sensing applications (in Chinese). Chinese academy of sciences, Beijing.

Li Z., Qi S. and Wei D. (2018). Empirical Research on the Relationship between Natural Gas Consumption and Economic Growth in the Northeast Asia. Energy and Environment.

Liu L.Y., Jing X., Wang J.H. and Zhao C.J. (2009). Analysis of the changes of vegetation coverage of western Beijing mountainous areas using remote sensing and GIS. Environmental Monitoring and Assessment. 153(1-4), 339-349.

Liu X., Zhang J., Zhu X., Pan Y., Liu Y., Zhang D. and Lin Z. (2014). Spatiotemporal changes in vegetation coverage and its driving factors in the Three-River Headwaters Region during 2000-2011. Journal of Geographical Sciences. 24, 288-302

Lu X.H., Jensen K.H., Jin M.G. and Wang P.F. (2017). Effect of unsaturated flow model conceptualization on the dynamic response of an integrated distributed hydrological model. Applied Ecology and Environmental Research. 15(3), 91-103.

Luo H.F., Miao F., Ye C.M. and Zhao G.X. (2013). Vegetation coverage change of Maoxian county before and after Wenchuan earthquake (in Chinese). Bulletin of soil and water conservation. 33(03), 202-205.

Maas S. (1998). Estimating cotton canopy ground cover from remotely sensed scene reflectance. Agronomy Journal. 90(03), 384-388.
Mi C., Zhang Z.W. and Huang Y.F. (2016). A Fast-Automated Vision System for Container Corner Casting Recognition. Journal of Marine Science and Technology. 24(1), 54-60.

Mohammed G.A.E.T. (2018). Productivity of Pure Stands and Intercropped Forage Sorghum and Hyacinth Bean. Malaysian Journal of Sustainable Agriculture. 2(1), 5-6.

Peng D.L. and Hua Y.C. (2008). Dynamic Monitoring of the Vegetation Restoration in Yanqing County (in Chinese). Journal of Central South University of Forestry \& Technology. 28(04), 159-164.

Peng J., Liu Y.H., Shen H. and Han Y.N. (2012). Vegetation coverage change and associated driving forces in mountain areas of Northwestern Yunnan, China using RS and GIS. Environmental Monitoring and Assessment. 184(08), 4787-4798.

Purevdorj T.S., Tateishi R., Ishiyama T. and Honda Y. (1998). Relationships between percent vegetation cover and vegetation indices. International Journal of Remote Sensing. 19(18), 3519-3535.

Qin W., Zhu Q.K., Zhang X.X., Li W.H. and Fang B. (2006). Review of vegetation covering and its measuring and calculating method (in Chinese). Journal of Northwest A\&F University (Natural Science Edition). 34(09), 163-170.

Razali M.A.A. and Said F.M. (2017). Red pigment production by monascus purpureus in stirred-drum bioreactor. Science Heritage Journal. 1(1), 13-15.

Rogers J.N., Parrish C.E., Ward L.G. and Burdick D.M. (2016). Assessment of Elevation Uncertainty in Salt Marsh Environments using Discrete-Return and FullWaveform Lidar. Journal of Coastal Research. (76), 107-122.

Shen Y., Zhao N., Xia M. and Du X. (2017). A Deep QLearning Network for Ship Stowage Planning Problem. Polish Maritime Research. 24(Si), 102-109. DOI: 10.1515/pomr-2017-0111.

Singh A., Kewat M.L. and Sondhia S. (2018). Studies on the effect of day time application of herbicide mesosulfuronmethyl on soil microbial communities of wheat rhizosphere. Journal of Environmental Biology. 39(1), 59-65. doi: 10.22438/jeb/39/1/MRN-562.

Tian Y., Fang Z.L., Xie Q., Pan H.L. and Liu X.L. (2014). Damages situations by Wenchuan earthquake and recovery status of vegetations in upper Minjiang river basin (in Chinese). Resources and Environment in the Yangtze Basin. 23(05), 735-740.

Xu J.C., Tang B. and Lu T. (2013). Monitoring the riparian vegetation cover after the Wenchuan earthquake along the Minjiang river valley based on multi-temporal landsat TM images: a case study of the Yingxiu-Wenchuan section (in Chinese). Acta Ecologica Sinica. 33(16), 4966-4974. 
Yang A., Han Y., Li S., Xing H., Pan Y. and Liu W. (2017). Synthesis and comparison of photocatalytic properties for Bi2WO6 nanofibers and hierarchical microspheres. Journal of Alloys and Compounds. 695, 915-921. DOI: 10.1016/j.jallcom.2016.10.188.

Yang B., Zhang J.F. and Li M.J. (2014). Evaluation of environmental vulnerability in the upper reaches of the Minjiang river (in Chinese). Remote sensing for land \& resources. 26(04), 138-144.

Yao J., Ding J. and Ai N.S. (2004). Assessment of ecological vulnerability in upper reaches of Mingjiang river (in Chinese). Resources and Environment in the Yangtze Basin. 13(04), 380-383.

Ye C.M., Han L. and Miao F. (2012). Monitoring and analysis of vegetation using remote sensing in 5.12 Wenchuan earthquake region (in Chinese). Progress in geophysics. 27(05), 1922-1928.

Ye Y.Q., Chen G.J. and Fan H. (2002a). Vulnerability of the eco-environment in the upper reaches of Minjiang river (in Chinese). Resources and Environment in the Yangtze Basin. 11(04), 383-387.

Ye Y.Q., Chen G.J. and Yang D.G. (2002b). Problems and management countermeasures in the upper reach of Minjiang river (in Chinese). Chongqing Environmental Science. 24(01), 2-4.

Zaidi N.A., Hamid A.A.A. and Hamid H.A. (2017). Lactic acid bacteria with antimicrobial properties isolated from the instestines of japanese quail (Coturnix Coturnix Japonica). Science Heritage Journal. 1(1), 10-12.
Zhang G.L., Xu X.1., Zhou C.P., Zhang H.B. and Ouyang H. (2011). Responses of vegetation changes to climatic variations in Hulun Buir Grassland in past 30 years (in Chinese). Acta Ecologica Sinica. 66(01), 47-58.

Zhang J. (2013). The continuous vegetation coverage of remote sensing monitoring of time and space (in Chinese). University of Chinese academy of sciences, Beijing.

Zhang T.T. and Liu J. (1990). The research on the method of satellite image geometric correction (in Chinese). Radio engineering. 03, 12-21.

Zheng Y.Q., Qian Y.F., Miao M.Q., Yu G., Kong Y.S. and Zhang D.H. (2002a). The effects of vegetation change on regional climate I: simulation results (in Chinese). Acta Meteorologica Sinica. 60(01), 1-16.

Zheng Y.Q., Qian Y.F., Miao M.Q., Yu G., Kong Y.S. and Zhang D.H. (2002b). The effects of vegetation change on regional climate II: mechanisms (in Chinese). Acta Meteorologica Sinica. 60(01), 17-30.

Zhou Q., Robson M. and Pilesjo P. (1998). On the ground estimation of vegetation cover in Australian rangelands. International Journal of Remote Sensing. 19(09), 1815-1820. 